\title{
Síndrome de Behçet
}

\author{
Lauro Gilberto Nunes R*, Raquel Moresco V*, Marley G*, Cristina da Silva B*, \\ Matesanz Pérez, $\mathrm{P}^{* *}$
}

\section{RESUIMEN}

El Síndrome de Behçet es un desorden inflamatorio crónico, multisistémico de origen desconocido. El síndrome se caracteriza por la presencia de úlceras orales y genitales recurrentes, lesiones oculares y cutáneas, artritis, alteraciones en el sistema nervioso central y enfermedades vasculares. A la ulceración oral recurrente se la considera una de las manifestaciones más importantes del síndrome, y resultan fundamentales para el diagnóstico de acuerdo con los criterios de clasificación. Se presenta un caso clínico en el cual la paciente busca atención de sus lesiones aftosas recurrentes y a través de una atención multidisciplinaria se llega al diagnóstico.

Palabras clave: Síndrome de Behçet. Desorden multisistémico. Ulceración oral recurrente.

\section{SUMMARY}

Behçet disease is a multi-systemic, chronic inflammatory disorder of unknown etiology. It is characterized by recurrent genital and oral ulcerations, ocular and cutaneous lesions, SNC alterations, involvement of the articulations and cardiovascular alterations. The oral ulcers can be big, small and herpetic-form, with a typical aftose distribution. The Behçet disease diagnostic is based on the clinical signs and symptoms of the various anatomic regions affected. The most common used drugs for the treatment are corticosteroids and immune suppressors. We are presenting a clinical case where, through the clinical manifestations of the oral lesions and multidisciplinary treatment, the diagnosis of disease was reached.

Key words: Behçet disease. Multi-systemic disorder. Oral ulcers.

Aceptado para publicación: Septiembre 2004.

* Departamento de Medicina Oral, Academic Hospital (HCPA), Universidad Federal de Río Grande do Sul, Porto Alegre, Brazil.

** Licenciada en Odontología en la U.C.M. Doctorado de la U.C.M., Madrid, España.

Lauro Gilberto Nunes R, Raquel Moresco V, Marley G, Cristina da Silva B, Matesanz Pérez, P. Síndrome de Behçet. Av. Odontoestomatol 2004; 21-4: 183-187.

\section{INTRODUCCIÓN}

El Síndrome de Behçet fue descrito por primera vez en 1937 por el Prof. Hulusi Behçet, un dermatólogo turco del que toma el nombre este cuadro en el que aparecen úlceras a nivel genital y oral, así como lesiones recurrentes en los ojos ${ }^{3}$. Algunos autores, interesados por la historia de la enfermedad, decidieron llamarla Síndrome de Adamantites-Behçet e honor a los oftalmólogos benedictos adamantitos, quienes describieron un caso en el año 1930, en el cual analizaban los síntomas principales de la enfermedad. Puede que Hipócrates, que vivió en la antigua Grecia en el 450 d.C. ${ }^{6}$, ya conociera la enfermedad, sin embargo, a pesar de la extensa bibliografía publicada acerca de este tema, la etiopatogenia de este cuadro está aún sin aclarar. Parece estar estrechamente relacionado con el complejo de histocompatibilidad antígeno HLA-B51 ${ }^{18}$. La mayor incidencia del Síndrome de Behçet se observa en Japón 


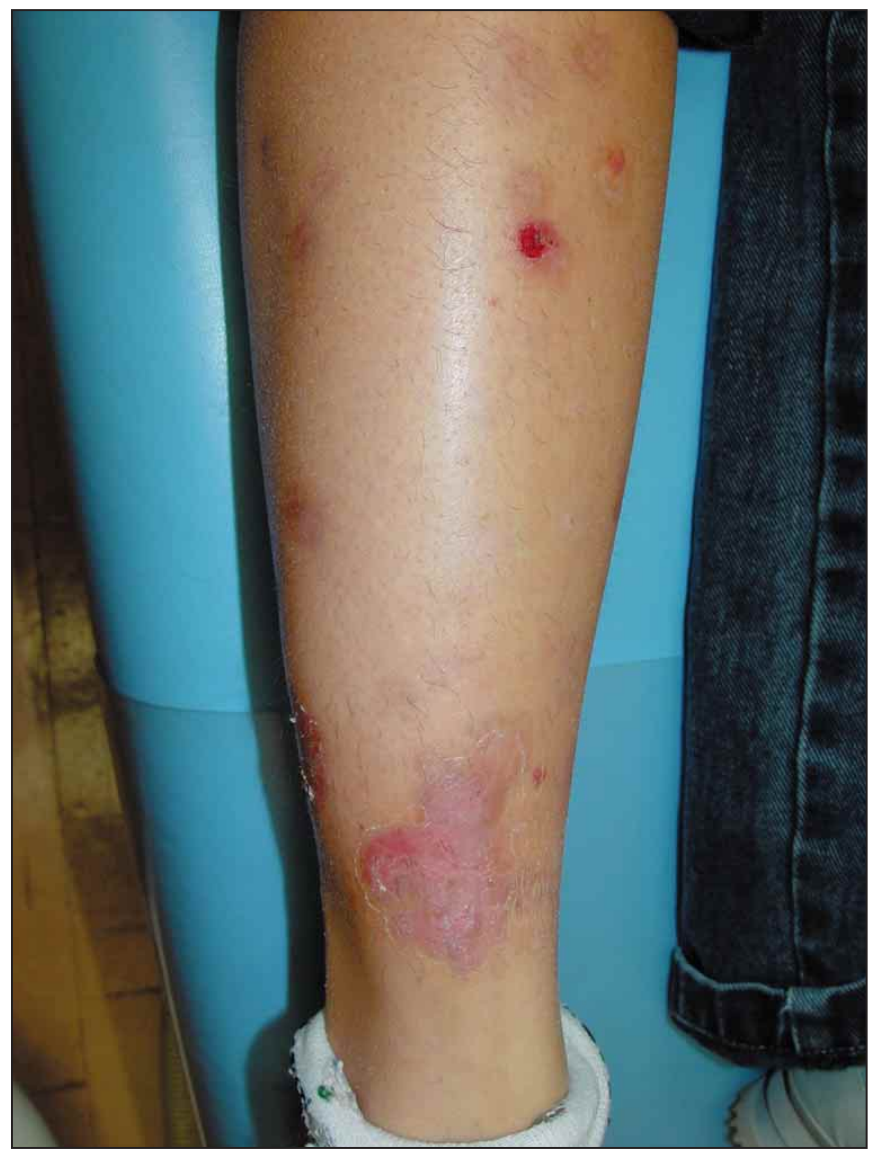

Fig. 1. Lesión cutánea en miembro inferior.

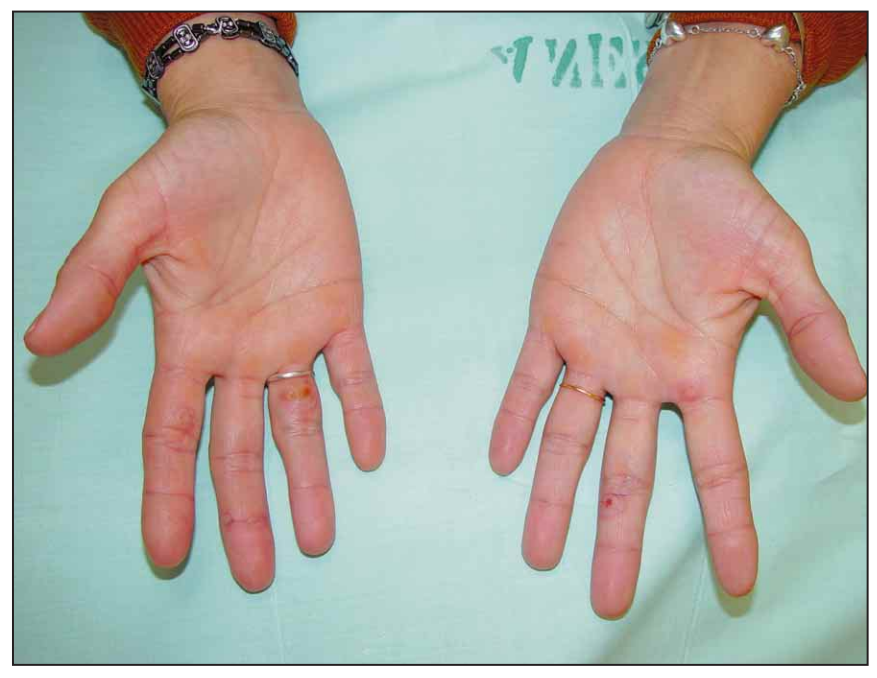

Fig. 2. Lesiones en distinto estadio de evolución; micropópulos y úlceras en los dedos.

y en los países del este del Mediterráneo relacionados con la antigua "ruta de la plata"14, aparece más en hombres que en mujeres ${ }^{15}$ y comienza en la tercera década de la vida. Raramente se desarrolla en

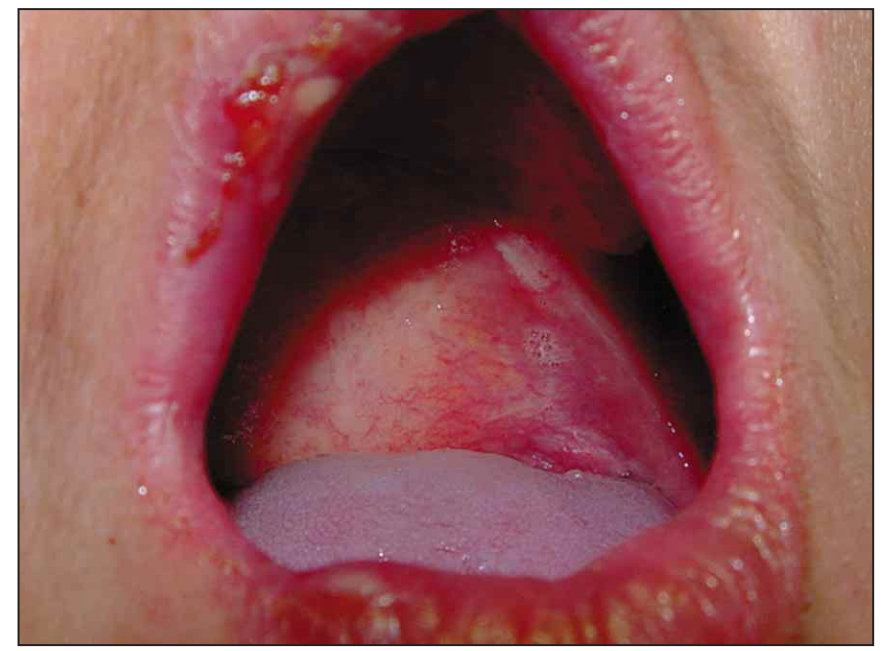

Fig. 3. Ulceras aftosas recurrentes en la mucosa labial.

niños y es especialmente agresivo en varones adultos jóvenes ${ }^{8}$. El diagnóstico está basado en los criterios clínicos establecidos por el Grupo de Estudio Internacional ${ }^{9}$, entre los que ha de constatarse la presencia de úlceras orales recurrentes asociadas a otros dos criterios, como pueden ser: lesiones oculares, lesiones cutáneas y test de pathergy positivo ${ }^{9}$. (Figs. 1, 2 y 3).

Las úlceras aftosas en la cavidad oral se consideran uno de los síntomas más importantes de este síndrome, y muchas veces resultan ser el primer signo objetivable de la enfermedad. Estas úlceras pueden ser de tres tipos: menores, mayores y herpéticas.

Entre las lesiones cutáneas puede observarse el eritema nodoso, que suele desarrollarse en las extremidades inferiores, aunque también puede aparecer en los brazos, el cuello y la cara ${ }^{8}$.

Las lesiones foliculares y las erupciones pápulo-pustulosas, inducidas por reacciones vasculares a través de los neutrófilos se consideran también manifestaciones cutáneas del síndrome que pueden ayudar al diagnóstico ${ }^{10}$.

La prueba del pathergy cutáneo se utiliza también como prueba diagnóstica. Origina una pústula inespecífica causada por el pinchazo de una aguja tras 24-48 horas en el lugar de la inyección en aproximadamente un $40 \%$ de los pacientes, especialmente mientras se encuentran en el periodo activo de la enfermedad. Algunos autores recomiendan el uso de 


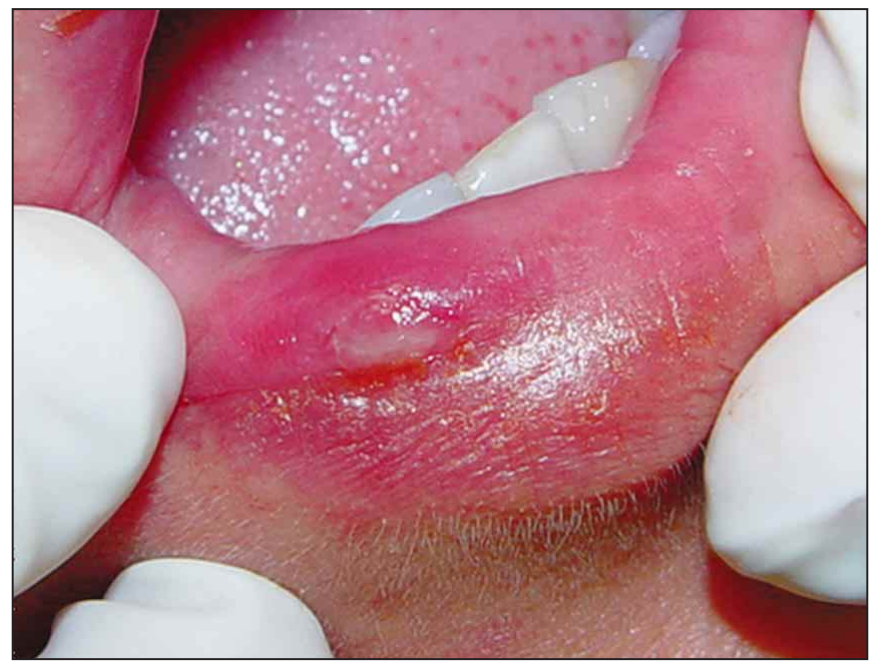

Fig. 4. Lesiones olorosas en labio inferior.

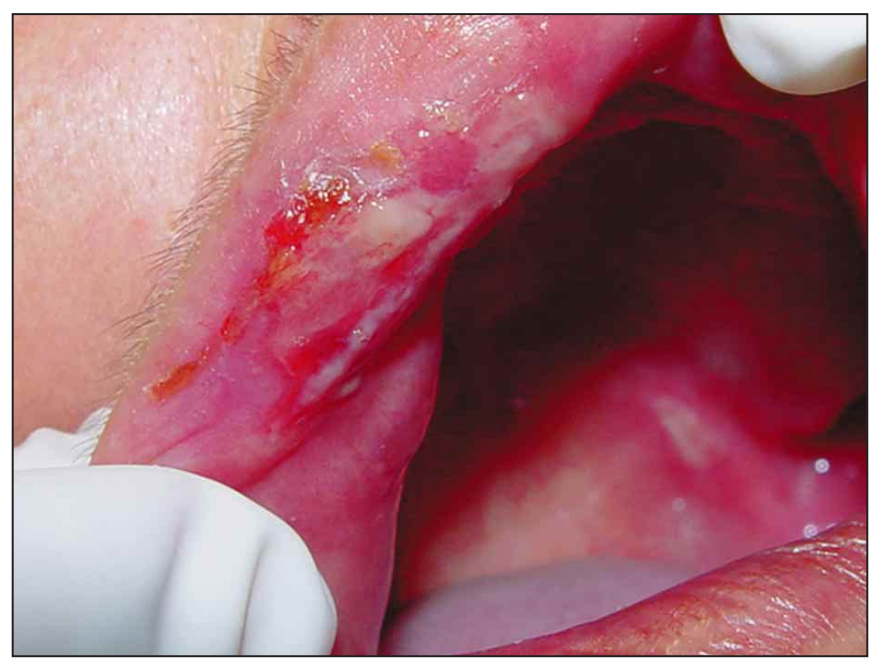

Fig. 5. Lesiones ulcerosas en comisura labial.

este test y sugieren que se emplee en el labio inferior $^{16}$.

Hasta el momento no puede decirse que exista un tratamiento específico para este cuadro. Los fármacos más comúnmente utilizados son los corticoesteroides, tanto por vía sistémica como local, asociados a inmunosupresores ${ }^{7,9}$, tales como reguladores inmunológicos ${ }^{12}$ y agentes citostáticos ${ }^{13,17}$.

El tratamiento del Síndrome de Behçet está en función de las manifestaciones clínicas que presente el paciente. En los casos en los que aparezcan úlceras orales dolorosas se recomienda el uso de corticoides y enjuagues con tetraciclina dos o tres veces al día.

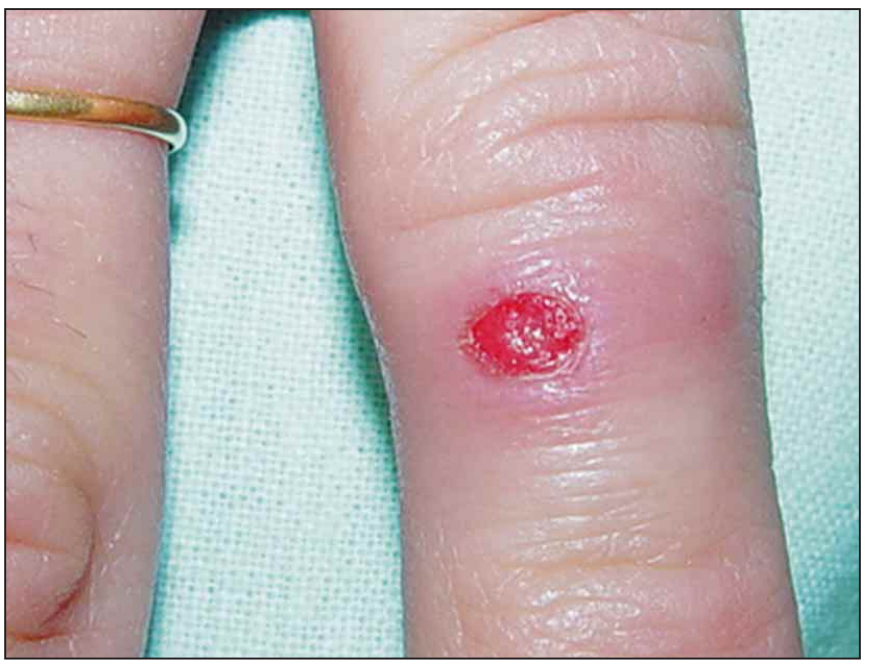

Fig. 6. Lesiones en los dedos de la mano.

\section{CASO CLÍNICO}

La paciente I.C.O., de 35 años, con leucoedema y de ascendencia portuguesa, fue remitida al departamento de Medicina Oral del hospital en junio de 2003 por el ambulatorio al que acudía a revisarse ciertas lesiones orales dolorosas que le aparecían de forma recurrente.

Durante la exploración intraoral se observaron lesiones ulcerosas en la parte posterior del paladar así como en la mucosa labial inferior de aproximadamente 5/10 mm de diámetro. La paciente refería además una cierta sensación de quemazón en las manos y lesiones del mismo tipo en otras localizaciones del cuerpo. Para el análisis de las lesiones se la remitió al servicio de cirugía vascular, donde se estableció el diagnóstico de presunción de vasculitis. Se le pidieron pruebas tales como: análisis de sangre, Hsv, Kttp, inmunofluorescencia para Lues, Tp, serología para Lues, anti-VIH, factor reumatoide, proteinograma, factor antinuclear, C3 y C4 del complemento, VDRL e IgG e IgM Herpes Simple pero no se llegó a ningún resultado significativo.

Dada la posibilidad de tratarse de un Síndrome de Behçet, se envió a la paciente al servicio de reumatología donde refirió la aparición de lesiones ulceradas recurrentes a nivel oral, en piernas y manos. Comentó haber tenido un proceso similar a los 17 y a los 28 años durante alrededor de un mes. Refirió además episodios de conjuntivitis unilateral (con ojos rojos, prurito y secreción purulenta) y comentó 
haber perdido 7 kilos en el mes de enero como consecuencia del dolor que le originaban las lesiones, el cual apenas le permití siquiera comer. No parecía haber habido casos similares en su familia y no parecía haber alteraciones neurológicas ni convulsiones asociadas. La paciente comentó haber tenido sensación de hormigueo en las manos durante más de una hora.

Se descartó un cuadro de trombosis; la paciente presentaba lesiones en distinto estadíos de evolución tales como: micropápulas, úlceras en los dedos, en los miembros inferiores y en las nalgas. Presentaba además cierto grado de hiperemia conjuntival en el ojo izquierdo y no había lesiones en el perineo ni artritis. Se le hizo el test de pathergy y, tras resultar ser positivo, se le indicó que tomara $20 \mathrm{mg}$ de prednisona por las mañanas, $20 \mathrm{mg}$ por las noches y 0,5 mg de inmunosupresores dos veces al día durante un mes. Durante este tiempo las lesiones fueron desapareciendo y se le redujo la dosis matutina de prednisona a la mitad.

Tras 45 días, las lesiones volvieron a aparecer y se restableció la dosis inicial de prednisona. Posteriormente el cuadro se estabilizó y la paciente no ha vuelto a presentar nuevas lesiones. (Figs. 4, 5 y 6).

\section{DISCUSIÓN}

La queja principal de la paciente era el gran dolor que le originaban las lesiones orales, el cual llegaba incluso a impedirle la ingesta. Estas lesiones miden alrededor de 5/10 mm de diámetro y suelen localizarse en los labios, la encía, la lengua, la mucosa yugal y la faringe? ${ }^{7}$ Resulta importante el papel del odontólogo en el diagnóstico precoz de este cuadro, ya que las lesiones orales representan uno de los signos más evidentes para la detección del síndrome de Behçet y aparecen en un $90 \%$ de los casos.

El hecho de que en un $42 \%$ de los casos aparezcan anticuerpos circulantes en la mucosa oral hace pensar en un cuadro de etiología autoinmune ${ }^{7}$. Los depósitos de C3 y C4 en las paredes de los vasos y la formación de inmunocomplejos con IgA, IgG e
IgM parecen corroborar esta teoría ${ }^{11}$. En el caso presentado estos valores no presentaban alteraciones.

La paciente presentaba hiperemia conjuntival e historia previa de conjuntivitis. Las lesiones oculares aparecen en un 50/60\% de los casos, siendo especialmente frecuentes la uveítis, que puede incluso desembocar en una ceguera. Se han descrito también casos de conjuntivitis y esclerosis ${ }^{5}$.

Las manifestaciones cutáneas, tales como las encontradas en la paciente del caso (eritema multiforme, acné, etc) están consideradas también como otro de los criterios diagnósticos de acuerdo a lo establecido por el comité internacional que estudia la enfermedad $^{9}$.

En este caso, el tratamiento multidisciplinar fue crucial para el diagnóstico y tratamiento correcto de las lesiones.

\section{BIBLIOGRAFÍA}

1. Akmaz Ö, Erel A, Gürer MA. Comparrison of histopathologic and clinical evaluations of pathergy test in Behçet's disease. Int J Dermatol 2000; 39:121-5.

2. Arbesfeld, S. J.; Kurban, A. K. Behçet's disease. New perspectives on an enigmatic syndrome. Journal of the American Academy of Dermatology, 19. (5): 767-779, nov. 1988.

3. Behçet $\mathrm{H}$. Ueber rezidiverende aphtoese, durch ein vírus verur sachte Geschwuere am mund am Auge und an den Genitalien. Dermatol Wochenschr 1937; 105:1152.

4. Benamour, S.; Zerquial, B.; Bennis, R. et alii. Maladie de Behçet 316 cases. La Pressse Médicale, 19. (32): 1485-1489, Oct.1990.

5. Betancor-Leon P. Manifestaciones insólitas de la enfermidad de Behçet. A propósito de una observación. Rev Clin Esp 1978; 14: 207-10 
6. Feigenbaum A. Description of Behçet's syndrome in the Hippocratic third book of endemic diseases. Br J Ophthalmol 1956; 40: 355-7.

7. Garcia A., Syndrome de Behçet: presentación de un caso clínico. Avances 2001; vol.17. n4.

8. Gürler A. Boyvat, A., Tursen, U. Clinical manifestations of Behçet's disease: an analysis of 2147 patients. Yonsei Med J 1997; 38: 423-5.

9. International Study Group of Behçet 's disease. Criteriafor diagnosis of Behçet disease. Lancet 1990; 335: 1078-80.

10, Kalbian, V. V.; Challis, M. T. Behçet's disease. Report of twelve cases with three manifesting as papilledema. The American Journal of Medicine, 49: 823-9, dec. 1970.

11. Lehner T, Batchelor JR, et al. An inmunogenic basis for the tissue involvent in Behçet's Syndrome. Inmunology 1979; 37: 895-9.

12. Merieux P, Spitler LE., Paulus HE. Treatment of Behçet's disease with levamisole. ArthritisRheum 1981; 24:1.

13. Moreno-Moraga. Valor terapêutico de la colchicina em la enfermidad de Behçet. Med Clin 1981; 9: 8-20.
14. O’Duffy JD, Goldstein NP. Manifestaciones neurológicas en siete pacientes con enfermidad de Beçet. Am J Med (ed esp) 1976; 4: 127-35.

15. Renon, M.A; Zambrano, C. B.; Isolan, T. M. P.; Agostini, L. M. Síndrome de Behçet. Revista Gaúcha de Odontologia, 41 (5): 291-2, set-out. 1993.

16. Sharquie K. E., Al-Araji A. Hatem A. Oral pathergy test in Behçet disease. British Jounal of Dermatology. V.146. Issue 1. page 168. January 2002.

17. Stey O, Charaz N, et al. Thalidomide et colete ulcere dans la maladie de Behçet. Gastroenterol Clin Biol. 1989; 13:104.

18. Verity, D. H., Marr, J.E., Ohno, S., Wallace, G. R., Stanford, M. R.Behçet disease, the Silk Road and HLA-B51: historical ands geographical perspectives. Tissue Antigens. Volume 54 Issue 3 Page 231- September 1999.

19. Zouboulis C. C.; Keitel W. A Historical Review of Early Descriptions of Adamantites-Behçet Disease. Jounal of Investigative Dermatology. Volume 119. Issue 1. page 201. July 2002. 